\title{
Angústias Psicológicas Vivenciadas por Enfermeiros no Trabalho com Pacientes em Processo de Morte: Estudo Clínico-Qualitativo
}

\author{
Rodrigo Almeida Bastos ${ }^{1, *}$ \\ Orcid.org/0000-0002-6159-8048 \\ Alberto Manuel Quintana ${ }^{2}$ \\ Orcid.org/0000-0001-7356-6142 \\ Franco Carnevale ${ }^{3}$ \\ Orcid.org/0000-0001-7255-9979
}

\author{
${ }^{1}$ Universidade Estadual de Campinas, Campinas, SP, Brasil \\ ${ }^{2}$ Universidade Federal de Santa Maria, Santa Maria, RS, Brasil \\ ${ }^{3}$ Universidade McGill, Montreal, Canadá
}

\section{Resumo}

Esta pesquisa objetivou conhecer as angústias vivenciadas pelos enfermeiros no trabalho com pacientes em risco ou em processo de morte em uma unidade hemato-oncológica. Estudo clínico-qualitativo, realizado por meio de entrevistas individuais. Participaram desta pesquisa 06 enfermeiros da unidade hemato-oncológica de um hospital universitário. Os resultados foram reunidos em cinco categorias, as quais remetem à perda da autonomia profissional quando o enfermeiro se depara com a dificuldade de pensar o seu próprio trabalho. O trabalho com a criança com câncer parece ser símbolo de uma angústia maior em lidar com a morte. Ao mesmo tempo em que a melhora ou a esperança de cura dá motivação ao enfermeiro, a morte do paciente infantil tem o significado de impotência, tristeza e desesperança. Os enfermeiros, ao longo do processo de trabalho, têm insights sobre como a sua relação com o trabalho poderia ser melhorada, porém, no momento do sofrimento, a preocupação dos enfermeiros não foi ouvida. Há a necessidade de que instituições de saúde, equipes e o próprio enfermeiro percebam esse profissional como um sujeito ético, necessitando refletir seu trabalho para que haja possibilidade de planejar alguma forma de digerir a angústia do trabalho.

Keywords: Atitude frente à morte, Enfermagem, Psicologia da Saúde, estresse psicológico.

\section{Psychological Distress Experienced by Nurses who Work with Patients in Death Process: A Clinical-Qualitative Study}

\begin{abstract}
This research aimed to know the anguish experienced by nurses who work with patients in risk or in dying process in a hematology-oncology unit. A clinical-qualitative study, conducted through individual

* Endereço para correspondência: Universidade Estadual de Campinas, Departamento de Psicologia Médica e Psiquiatria, Prédio FCM11, $3^{\circ}$ andar, Rua Tessália Vieira de Camargo, 126, Cidade Universitária Zeferino Vaz, Campinas, SP, Brasil 13083-887. Fone: (75) 9 9210-8559. E-mail: almeidabastos.rodrigo@gmai.com Agradecimento: Agradecimento à Fundação de Amparo à Pesquisa do Estado do Rio Grande do Sul, a qual financiou esta pesquisa ao longo de dois anos.
\end{abstract}


interviews. The participants were 06 nurses from hematology-oncology unit of a university hospital. The results were grouped into five categories, which refer to the loss of professional autonomy when the nurse is faced with the difficulty of thinking about their own work. Working with children affected by cancer seems to be a symbol of greater anxiety in dealing with death. While that, the improvement or cure of hope brings motivation to nurse, the death of the child patient has the meaning of helplessness, sadness and hopelessness. Nurses throughout the work process have insights about how their relationship to work could be improved, but the nurses' concern has not been heard during the suffering. These findings emphasize the need for health care organizations, teams and even the nurses perceive this professional as an ethical subject, who needs to reflect their work to be able to plan some way to digest the anguish of working.

Keywords: Attitude to death, Nursing, Health Psychology, psychological stress.

\section{Angustia de Enfermeras en Trabajo con Pacientes en Proceso de la Muerte: Estudio Clínico-Cualitativo}

\section{Resumen}

Este estudio tuvo como objetivo conocer las angustias experimentado por enfermeros que trabajan con pacientes en riesgo o proceso de morir en una unidad de hemato-oncología. Estudio clínico-cualitativo, realizado a través de entrevistas individuales. Los participantes fueron 06 enfermeras de la unidad hemato-oncológica. Los resultados demuestran la pérdida de la autonomía profesional cuando la enfermera se enfrenta a la dificultad de pensar sobre su propio trabajo. El trabajo con niños con cáncer parece ser un símbolo de mayor ansiedad para hacer frente a la muerte. La mejoría o curación de la esperanza motivación para la enfermera, la muerte del paciente infantil tiene el significado de impotencia, tristeza y desesperanza. Enfermeras, a lo largo del proceso laboral, tienen ideas sobre cómo se podría mejorar su relación con el trabajo, pero la preocupación de las enfermeras no se han escuchado durante el sufrimiento. Existe la necesidad de que las instituciones de salud, equipos e incluso las enfermeras perciben este profesional como sujeto que requiere reflejan su trabajo de modo que no hay posibilidad de planificar alguna manera de digerir la angustia de trabajo.

Palabras clave: Actitud frente a la muerte, Enfermería, Psicología de la Salud, Estrés Psicológico, Psicología.

Contextos socioculturais distintos ao longo da história vêm moldando a ideia que o homem tem da morte. Essa ideia dinâmica tem a força de transformar, ainda, os modos de vida de uma sociedade, tornando o significado da morte e do morrer um interessante reflexo do significado da própria vida para esta sociedade ou para o sujeito que a compõe. Da morte escancarada na idade média à morte interdita nos tempos atuais, o que se percebe é que sempre houve temor diante desse fenômeno. Temor este traduzido em angústias vivenciadas pelo homem, relacionadas à sua falta de controle sobre a morte e a seus sinais (Ariès, 2003).
Cuidar de quem está diante da morte é, dessa forma, um desafio particular do paradigma contemporâneo. O que antes era função da família passa a ser responsabilidade dos profissionais da saúde, embebidos de ciência e técnicas, teoricamente suficientes para o trabalho com pacientes em risco ou processo de morte (Ariès, 2003; Souza e Souza et al., 2013). Porém, nem só de ciência e técnica vive o homem. Os profissionais da saúde são, antes de tudo, sujeitos integrados a um paradigma político-social, no qual a morte deve ser evitada e a vida deve ser salva a qualquer custo (Borges \& Mendes, 2012). E é assim que a história da angústia desses profissionais, no contexto de morte, tem sua gênese. 
O enfermeiro se encaixa como personagem ativo nesse processo de angústia no cuidado com o outro. A vivência desse profissional no âmbito hospitalar, onde a morte espreita com maior proximidade, é caracterizada por uma batalha direta entre a vida e a morte dos pacientes. Como agravante, o enfermeiro é, nesse contexto, o responsável direto pela gestão do cuidado integral de todos os pacientes da unidade. Sua formação é caracterizada por cobranças e postura firme, sendo, frequentemente, quase impedidos de expressar o que realmente sentem sobre o trabalho (Santos \& Bueno, 2010).

Ao longo das suas vivências, frequentemente os enfermeiros têm de lidar com situações de morte dos sujeitos sob seus cuidados. As dificuldades encontradas nesses casos estão relacionadas, em grande parte, à própria dificuldade do profissional em perceber a morte como parte integrante da vida, refletindo em cada caso suas próprias angústias sobre o tema. A constante convivência com situações de morte não isenta esses profissionais da expressão de sentimentos de angústia e sofrimento, sendo necessária a compreensão dessas vivências para perceber o que, afinal, significa esse convívio para o enfermeiro (Souza e Souza et al., 2013). A necessidade dessa compreensão vai além do desejo em aprimorar a assistência de enfermagem. Compreender essas vivências significa dar voz a esse sujeito cuidador, que geralmente se cala diante da angústia de cuidar da dor do outro. Falar sobre as vivências angustiantes torna o sujeito reflexivo à sua prática, sendo o processo assistencial em saúde beneficiado por consequência do aperfeiçoamento do enfermeiro enquanto sujeito.

Considerando este contexto, porém, privilegiando a investigação sobre as reflexões dos sujeitos de pesquisa, este artigo objetiva apresentar os resultados das entrevistas sobre as angústias vivenciadas pelos enfermeiros no trabalho com pacientes em risco ou em processo de morte, em uma unidade hemato-oncológica. O setor hemato-oncológico foi um campo de estudo revelador sobre essas vivências, visto que se trata de um ambiente de plano terapêutico prolongado e exigente em termos de conhecimento técnico-científico. A atenção hemato-oncológica expõe o profissional às relações sociais e emocionais com os sujeitos envolvidos no tratamento. $\mathrm{O}$ processo de trabalho nessa área expõe o cuidador a uma reflexão sobre a própria prática e, ainda, sobre a própria vida (Umann, Silva, Benavente, \& Guido, 2014).

\section{Método}

Trata-se de um estudo clínico-qualitativo, tendo os sentidos e as significações dos fenômenos como fundamento para a pesquisa e para o pesquisador (Turato, 2013). O estudo foi realizado na clínica hemato-oncológica de um hospital universitário no estado Rio Grande do Sul, ao longo do ano de 2015. A clínica hemato-oncológica foi escolhida para o trabalho de pesquisa dada a particularidade existente nessa unidade quanto às relações entre o enfermeiro, os pacientes/familiares e a equipe cuidadora.

\section{Participantes}

Participaram do estudo 06 enfermeiros da unidade hemato-oncológica de um hospital universitário, contemplando os setores de ambulatório quimioterápico e internação infantil. A unidade hemato-oncológica contempla quatro setores, a saber: Ambulatório de Quimioterapia, Internação Infantil, Internação Adulto e Centro de Transplante de Medula Óssea (CTMO), sendo participantes deste trabalho apenas os profissionais dos dois primeiros setores, visto critérios de disponibilidade ou interesse deles.

Entre os entrevistados, 05 eram mulheres e 01 homem, com idades entre 30 e 50 anos. $\mathrm{O}$ tempo de formado variou entre 09 e 25 anos e o tempo de vivência profissional no setor hemato-oncológico entre 04 meses e 20 anos. Os critérios de inclusão foram: exercer atividades profissionais com pacientes em risco ou em processo de morte e ter aceitado participar do estudo, assinando o Termo de Consentimento Livre Esclarecido (TCLE). Os enfermeiros em férias, licença maternidade, afastamento por licença médica ou para estudo de aperfeiçoamento acadêmico, bem como aqueles que não demonstraram interesse em participar do estudo foram inseridos nos critérios de exclusão. 


\section{Instrumentos}

A coleta de informações foi realizada por meio de entrevistas individuais, a partir de um roteiro estruturado semidirigido. A estratégia utilizada para identificar o número de participantes foi a saturação teórica (Turato, 2013). O roteiro de entrevista, comum a todos, abordou aspectos da qualidade de vida e do trabalho com pacientes em risco ou processo de morte. Esse roteiro teve a função de delimitar as questões indispensáveis para a pesquisa durante a entrevista, orientando o pesquisador a estimular a fala do entrevistado acerca dos temas (Minayo, 2010). No caso deste estudo, orientou a compreensão das vivências de autocuidado dos enfermeiros, cujo trabalho é, dentre outros, a aproximação com o momento ou processo de morte dos pacientes internados na unidade de hemato-oncologia.

\section{Procedimento de Coleta de Dados}

Para que a coleta fosse iniciada, foi encaminhada cópia do projeto de pesquisa à instituição alvo do estudo. Tendo sido julgado procedente pelos responsáveis, foi submetido à avaliação do Comitê de Ética em Pesquisa (CEP). Após parecer favorável pelo CEP, houve o primeiro contato com a unidade para o convite dos participantes. A fase de coleta das informações ocorreu no período de julho de 2015 a novembro de 2015. Utilizando-se do instrumento de pesquisa, realizou-se uma entrevista de aculturação, cuja finalidade foi, segundo Turato (2013), "permitir ao pesquisador vivenciar seu processo de assimilação do modo de pensar daquela população-alvo, em cujo ambiente ficará imerso temporariamente" (p. 316).

\section{Procedimentos Éticos}

$\mathrm{O}$ estudo amparou-se na Resolução $\mathrm{n}^{\circ}$ 466/2012 do Conselho Nacional de Saúde, regulamentadora das pesquisas com seres humanos. As atividades de campo ocorreram após a aprovação pelo Comitê de Ética em Pesquisa da instituição onde foi realizada, sendo o projeto aprovado sob o número CAAE 40608715.9.0000.5346. Com o objetivo de preservar o anonimato dos participantes, as falas que ilustram as categorias foram legendadas, conforme segue: E (Enfermeiro), seguido da numeração entre 1 e 6 , bem como do tempo de vivência no serviço de hemato-oncologia, no formato de estimativa.

\section{Resultados e Discussão}

A partir da análise das informações colhidas ao longo das entrevistas, emergiram algumas categorias que fazem referência às dificuldades vivenciadas pelos enfermeiros que trabalham no contexto da morte em hemato-oncologia. As categorias serão expostas e discutidas a seguir, de forma a perceber a correlação entre as várias angústias vividas pelos enfermeiros, diante dos diversos fatores que permeiam seu trabalho com pacientes em risco ou em processo de morte.

\section{Para Além do Arco: A Qualidade de Vida está Fora do Trabalho}

Os relatos dos participantes fazem referência à qualidade de vida como resultado de experiências vividas fora do ambiente de trabalho. Além desse "Arco" que, enquanto estrutura física presente na via de acesso ao espaço hospitalar, simboliza para os enfermeiros locais o limite entre a entrada e a saída do ambiente de trabalho. Os relatos sugerem que existe dificuldade em refletir sobre os momentos que interferem na própria qualidade de vida. O desejo é de encontrar fora do espaço laboral os momentos de satisfação e a tranquilidade que o hospital não contempla. A qualidade de vida é um constructo subjetivo e multidimensional, sendo vivenciado de forma singular pelo sujeito, ao acionar sua subjetividade, sua relação consigo mesmo (Colomé \& Oliveira, 2012).

E assim, tu pensar em ter momentos de lazer, de fazer coisas fora do ambiente de trabalho... então eu acho que é uma coisa que a gente deveria pensar mais, mas a gente só para pra pensar quando vem alguém e pergunta... como aqui nesse momento. (E3, entre 05 e 10 anos no serviço)

No trabalho hospitalar, a subjetividade do enfermeiro recebe diferentes demandas por meio do tipo de trabalho realizado, tendo a vida e a morte como fontes de reflexão desafiadora em 
sua prática (Borges \& Mendes, 2012). Se o trabalho com a morte causa incômodo, agressão e peso à rotina diária, o depoimento sugere que a qualidade de vida, enquanto significado de paz de espírito e tranquilidade, está localizada fora do ambiente de trabalho.

A gente convive num lugar tão... pesado com... com... Tanto fisicamente, né, que a gente vê situações... [suspira]... verdadeiras aberrações, né, de questão anatômica, tumorações e tudo... e isso agride. . . Ter tranquilidade, paz de espírito. Isso é qualidade de vida pra mim. (E1, entre 05 e 10 anos no serviço)

O significado do trabalho como fator de angústia para os entrevistados pode ser compreendido como uma consequência da filosofia institucional hospitalar e do tipo de trabalho realizado. Os hospitais geralmente procuram modelos assistenciais e de gestão a fim de alcançarem resultados capazes de otimizar recursos e garantir a melhoria do serviço oferecido. Esse pensamento institucional limita a participação do trabalhador de saúde nas discussões sobre a melhoria dos serviços, pois é esse trabalhador que deve se adaptar à instituição e não o contrário. Esse contexto propicia a uma baixa associação, por parte do trabalhador, entre seu processo de trabalho e sua qualidade de vida, fazendo com que esse sujeito procure fora do ambiente de trabalho os recursos de satisfação com a vida (Tschiedel \& Monteiro, 2013). O resultado gera, nesse profissional, conflitos e desgaste psíquico, comprometendo, inclusive, a capacidade de pensar sobre o cuidado de si.

Acho que hoje em dia eu consigo ter um pouco mais [de qualidade de vida]. Mas eu acho que às vezes a instituição poderia ofertar algumas coisas que ajudassem mais. Eu acho que deveriam ter coisas aqui dentro do hospital. (E3, entre 05 e 10 anos no serviço) Não é à toa que o tipo de trabalho exercido pelo enfermeiro na hemato-oncologia tem tamanha competência em angustiá-lo e provocar esse desgaste psíquico. A particularidade desse serviço é a constante tensão pela espera da ocorrência daquela que é tão frequente quanto indesejada: a morte.

\section{Não Sei como Eu Lido: A Ocorrência do Óbito como Fator de Angústia Profissional}

A ocorrência do óbito: o ápice da angústia do profissional que trabalha com o vínculo e com os afetos advindos da relação com o paciente. Entre os relatos, um dilema surge e é respondido logo em seguida. A maturidade profissional leva a trabalhar melhor ou torna o profissional mais insensível à ocorrência do óbito? As falas sugerem que, no princípio da vida profissional, o enfermeiro ainda tem a oportunidade de lançar mão de estratégias para elaborar a perda de um paciente, porém, com o passar do tempo, o convívio com situações de morte parece enrijecer o processo de elaboração do luto profissional, tornando-o insensível como em um mecanismo de defesa. Importa perceber que a sensibilidade para as manifestações verbais e não verbais do paciente é uma ferramenta importante na identificação de necessidades singulares a cada um (Peterson \& Carvalho, 2011). Porém, perceber o imperceptível e lidar com as mobilizações que essa percepção gera no enfermeiro, se torna fonte de uma angústia que nem sempre se consegue elaborar.

E depois... depois era tanto óbito, que... não sei... não sei se tu se acostuma ou se tu vai trabalhando melhor, assim... E eu lembro que eu sempre dizia [aos familiares]: "Fala... fala com ele... Fala com ele, toca. Diz que você ama, pede desculpa". Eu lembro, assim, que eu trabalhava [antigamente na UTI] melhor essas questões, assim. (E1, entre 05 e 10 anos no serviço)

A convivência frequente com a morte dos pacientes não isenta os profissionais da mobilização de sentimentos de angústia, mas do contrário, dessa angústia deve surgir uma resignificação da morte e da própria vida do profissional. Porém, suportes são necessários para que haja meios de resignificação desse sofrimento, caso contrário, a impotência e a tristeza são geradas a partir da perda do controle sobre a vida (Sanches \& Carvalho, 2009; Souza e Souza et al., 2013).

Sentimento de tristeza, né... e sentimento de impotência, que não tem o que tu fazer. De tu ta ali e não poder fazer nada... e ele vinha 
fazendo medicações, os analgésicos, morfina direto, dipirona, tudo que pudesse imaginar pra dor e não. Não sei como que eu lido... eu acho que... que é o tempo que vai... que vai passando, sabe... que vai amenizando aquele sentimento. Aquele pensamento... (E4, até 01 ano no serviço)

O enfermeiro é, portanto, ator de um ciclo de angústia profissional, pois sua formação não contempla o enfrentamento da frustração pelo óbito do seu paciente, reduzindo seu arsenal de estratégias de elaboração, tornando-o psiquicamente vulnerável no campo de prática (Souza e Souza et al., 2013). Esse campo, na figura da instituição hospitalar, exige um trabalho que prioriza produtividade e racionalidade na assistência, tornando restritos os momentos de reflexão sobre a prática profissional, sobre as limitações do profissional e seus desejos enquanto ser humano, cujo trabalho é cuidar do outro em um leito de morte.

Tu tem que... Tu tem que, na verdade, estar bem porque quem vai ficar ruim vai ser. . . o familiar. Ai se tu ficar ruim também, como é que tu vai poder ajudar, né. Então acho que por mais que de repente tu esteja chorando por dentro, tu tem que pelo menos transparecer um pouco de calma pra pessoa que vai estar ali na tua frente, pra mãe que está chorando. Imagina se tu choras junto com a mãe? Tem que parecer um pouco mais forte perante o familiar. (E4, até 01 ano no serviço)

A consequência dessa incompatibilidade ética, percebida nas falas dos entrevistados, é o sofrimento que se expressa por meio da insensibilidade ao contexto da morte e o surgimento de uma nova angústia: a de perceber um grau de toxicidade psíquica pelo vínculo criado.

\section{Prefiro me Afastar: O Vínculo Hostil}

Mesmo que a percepção sobre as angústias dos pacientes ou familiares seja prejudicada, a intenção é postergar ou descartar a ideia do vínculo e tentar não sofrer. É importante observar que esse fenômeno descrito nas falas a seguir sugere um grau de descaracterização do trabalho do enfermeiro. $\mathrm{O}$ enfermeiro cuida das necessi- dades biológicas e subjetivas dos sujeitos, necessitando calibrar regularmente sua capacidade em perceber as questões evidenciadas ou não-ditas pelos pacientes e familiares. Ao abrir mão dessa habilidade para seu trabalho, pode-se pensar em um tipo de despersonalização, ou seja, ela deixa de ter participação ativa na própria vida laboral, se tornando passiva, efetuando as atividades de forma quase automática, como sendo uma estranha a si mesmo.

Às vezes eu até tento me manter um pouco mais distante, né. Pra não sentir tanto o baque, né. Porque, por exemplo, têm colegas que... que sabem da vida do familiar, que conhecem, que sabem historia de vida, né... eu tento não me aprofundar muito. Eu acho que de repente sofra menos ou perceba menos isso, né. (E4, até 01 ano no serviço)

Vieira e Marques (2012) refletem que a equipe de saúde não utiliza a ferramenta da escuta no contexto de morte ou sofrimento geralmente porque isso remete a um sentimento de impotência diante do não saber. Dessa forma, é possível que o sentimento de impotência por parte de um profissional de saúde, diante da morte de um paciente, advenha da fala e escuta do outro, pois remete à falta de respostas sobre o que acontecerá. A escuta passa a ter, não de forma consciente, um caráter tóxico para o enfermeiro. Essa ideia de suposto saber inserida no profissional de saúde, que provoca essa frustração pelo não saber, encontra sua gênese na formação profissional organocêntrica, na filosofia institucional hospitalar e na própria cultura social, a qual orientam os indivíduos a se submeterem ao saber-poder da área da saúde, lançando ao profissional a obrigatoriedade do saber, o qual compra essa ideia (Foucault, 2010; Gimenes, 2013).

"A gente não pergunta, mas eles fazem questão de contar algumas coisas pra gente. Então acaba criando um vínculo... Por isso que é um pouco dificil trabalhar aqui. Porque emocionalmente acaba querendo não... acaba te envolvendo com eles" (E6, entre 15 e 20 anos no serviço).

De fato, a escuta do paciente/familiar deve ser desenvolvida e estimulada por meio da equipe. Porém, a dificuldade ou a negação dessa escuta, por parte dos profissionais da enfermagem, 
parece ter a necessidade de ser mais bem compreendida, pois parece se tratar de uma proteção psíquica contra a carga de angústia que recebe o enfermeiro ao entrar em contato com o sofrimento do outro. Daí a importância da equipe multiprofissional no apoio às deficiências não apenas técnicas, mas subjetivas da própria equipe. E, ao que parece nas falas que seguem, a carga de angústia é especialmente produzida no trabalho com a criança com câncer.

\section{Por que uma Criança?: O Emblema da Criança com Câncer}

A chegada abrupta da morte de uma criança se torna potencialmente danosa à psique do enfermeiro pela constante variação de sentimentos contraditórios, entre o conforto dos sorrisos em momentos de estabilidade terapêutica e a frustração pela piora do quadro clínico e a chegada da morte (Santos, Jesus, \& Portela, 2013). Em uma avaliação biopolítica, o conforto dos sorrisos da criança e a esperança de uma provável cura de um paciente clinicamente em processo terminal remetem ao retrado da dificuldade de aceitação da morte pelo profissional da saúde, formado para salvar vidas a qualquer custo. A relação entre o poder sobre a vida e aceitação da morte pelo enfermeiro, é de invasão ou violação desse suposto poder (Pelbart, 2008). A morte da criança parece ter um diferencial ainda mais angustiante ao se perceber essa violação do controle sobre a vida.

Então eu acho que é... a ordem cronológica que a gente espera que aconteça. Então a morte numa criança eu acho que inverte esse periodo que a gente considera normal. Então por isso eu acho que muitas pessoas veem como mais sofrido isso, né? Mais sensibilizador, assim... (E3, entre 05 e 10 anos no serviço)

As relações de poder existem naturalmente na vida dos sujeitos, influenciando a visão sobre o corpo e a mente. Os profissionais de saúde utilizam as ciências naturais como ferramenta de poder nessa relação, definindo a maneira como os sujeitos percebem, sentem e pensam sobre a vida e a morte. A velha potência da morte como símbolo do poder soberano, quando o fazer mor- rer era símbolo de poder, é recoberta pela administração dos corpos e pela gestão da vida, em que o fazer viver se torna hegemônico. Segundo Pelbart (2008), o corpo infantil ou adolescido é visto nesse sistema de poder sobre a vida como potencialmente produtivo, construindo para os profissionais da saúde uma formação baseada nessa gestão da vida. Dessa forma, o raciocínio clínico e as ações pessoais do profissional da saúde ponderam a potência produtiva da criança, percebendo-a em um ciclo natural de vida, objetivando a cura a qualquer custo e fazendo o profissional se perguntar no momento da morte: "por que uma criança?".

Enquanto tem tanta coisa acontecendo por ai, por que uma criança? Por que um adolescente? A gente acaba sofrendo muito. É impressionante como essas coisas são cíclicas. De repente não tem ninguém, ninguém passando mal. Dali a pouco é um ciclo de cinco, seis morrendo e, sabe... então é... é bastante complicado e é impressionante. (E2, entre 15 e 20 anos no serviço)

Morte fora de lugar evidencia a total impotência em exercer um controle sobre ela. Em meio a discursos de sofrimento ante a morte de crianças, algumas contradições não são raras, justamente pelo fato da criança ter um papel consolador em momentos de estabilidade ou recuperação (Poles \& Bousso, 2006). Porém, ao se deparar com a morte dela, o enfermeiro tende a reaver o sofrimento de perda de forma, talvez, mais intensa. O "melhor contato . . . de todos", passa a se tornar "a pior de todas" as experiências.

Ele [a criança] vinha e pedia pra chamar meu nome. E dai foi o contato melhor que eu tive de todos. E ai também, ele nesse dia... ele passou mal, ele ficou ruim, ai acabou indo pra CTI comigo, né. . . . Então acho que essa ainda foi a... pior de todas assim... que foi com quem eu mais tive contato, né. Me envolvi, assim... (E4, até 01 ano no serviço)

Os conflitos enfrentados pelo enfermeiro em sua prática junto a pacientes em processo de morte deveriam ser acompanhados por uma rede de apoio, seja pela iniciativa da gestão ou pela própria equipe de trabalho. Quando existe 
um suporte defasado a esses conflitos morais, o profissional passa a sofrer de forma a sentir-se culpado, frustrado ou impotente (Barlem et al., 2013). Os discursos que seguem, sugerem um sofrimento na dimensão moral da atividade do enfermeiro.

\section{Qual o Motivo de Tanta Angústia? Desesperança: o Sofrimento Moral}

A angústia provocada na dimensão moral do sujeito, chamado de sofrimento moral, é decorrente da incoerência entre as convicções éticas e morais desse sujeito e suas ações. Na prática, o sujeito sabe o que deveria ser feito segundo seus valores, mas se percebe impossibilitado de agir, seja por erros de julgamento, falhas pessoais ou mesmo circunstâncias alheias ao controle pessoal (Barlem, Lunardi, Lunardi, Dalmolin, \& Tomaschewski, 2012).

Nos discursos que seguem, é percebido que dificilmente se pode refletir sobre o que é melhor a ser feito diante de tantas normas e rotinas que regram a vida do profissional. $\mathrm{O}$ enfermeiro é conduzido a agir mais em vigilância às normas e menos como cuidador. O resultado é um paciente coibido, que engole seus medos, envolto a tecnologias duras, e um profissional ou equipe que sofre pelo tipo de trabalho e pela impossibilidade de mudar sua rotina.

Ah! mas qual é o motivo de tanta angústia? sim... coisa que mais me deixa dessa forma assim... desesperança... é que a gente não tinha condições de mudar a situação. Essa... essa ausência de poder mudar algumas coisas. Que a gente via, tava ali, tava na nossa cara que tinha que mudar. Mas a gente não conseguia fazer... mudar essa realidade. (E2, entre 15 e 20 anos no serviço)

Desesperança e impotência perante os protocolos de assistência. Os profissionais são conduzidos a agirem em parceria com a incoerência do que acreditam ser o certo naquele instante. Situações pequenas que ao longo dos anos elevam a carga de angústia e do sofrimento, pois não há por onde escoar. O dano psíquico chega à dimensão tal que as ideações começam a ter um caráter de doença mental (Barbosa, Vieira,
Alves, \& Virgínio, 2012). A angústia e o sofrimento precisam sair de alguma forma, nem que seja por meio da extinção da própria vida.

Te dizer com toda franqueza que se eu não fiz besteira com minha vida algum dia foi... por... não sei por que. Mas sabe... a gente começa a se frustrar com muita coisa . . . toda uma situação muito ruim que a gente passa... então eu passei por esse momento de estresse, claro que também não... não procurei ajuda fora... mas que precisava sair, que precisava parar um momento... (E2, entre 15 e 20 anos no serviço)

Parar um momento para pensar, fazer o exercício da reflexão, tão difícil quando se trabalha nas tensões do contexto da morte e na impossibilidade de mudanças. É bem nítida na literatura a ideia de que as situações geradoras de sofrimento moral como o ambiente de trabalho angustiante, papéis ambíguos e a falta de clareza quanto às tarefas a serem realizadas têm efeitos adversos na saúde mental dos profissionais da saúde que lidam com a angústia do outro, em especial dos enfermeiros (Barbosa et al., 2012; Manetti \& Marziale, 2007). Essas situações são potencialmente geradoras de fenômenos como a depressão e ideação suicida, haja vista os sentimentos de vazio, de perda de identidade e dificuldade de nomear as experiências.

As experiências de sofrimento relatadas são geradas por situações onde o enfermeiro não consegue agir de acordo com o que se espera dele no trabalho com pacientes em processo de morte. A tensão gerada pode ser tamanha que a fantasia do fazer sofrer acaba surgindo, gerando sentimentos de culpa e impotência em situações onde não há potencial de negligência, imprudência ou imperícia.

Teve uma vez uma situação que eu fui, que dai eu entrei em sofrimento, mas... não era por óbito, mas era por um procedimento uma administração numa químio que eu fiz e que extravasou. Daí deu uma lesão no paciente e eu fiquei com aquela coisa que a culpa tinha sido minha . . . eu fiquei com aquilo me causando um sofrimento tão grande de responsabilidade pelo paciente . . . (E3, entre 05 e 10 anos no serviço) 
Os enfermeiros não têm liberdade para moldar os padrões éticos de sua própria profissão ou para agir de forma autônoma, justamente por uma questão sociopolítica (Carnevale, 2013) ou de relações de poder (Foucault, 2014). É importante que essa complexidade moral da prática da enfermagem seja reconhecida para que se possa perceber a influência na saúde psíquica do profissional e as consequências para a própria assistência (Carnevale, 2013).

É perceptível, ao longo dos discursos, que os profissionais, concomitante à descrição do seu próprio sofrimento, resoavam autorreflexões sobre eles. Eles conheciam o motivo da angústia, descreviam o conflito ético ao qual estavam inseridos e do qual, naquele momento, não conseguiam sair. Há a reflexão, como visto nesse último discurso, de uma autodefesa sobre a culpa que ela mesma havia significado para si naquela dada situação. Ou seja, os enfermeiros tiveram insights de como a sua assistência ou como a sua relação com o trabalho poderiam ser melhoradas. Porém, no momento do sofrimento, a preocupação dos enfermeiros não foi ouvida. Dar voz ao enfermeiro, espaço para a expressão dos sentimentos sobre a agência moral (Carnevale, 2013; Rodney et al., 2012), que envolve seu trabalho, o faz perceber que ele não está sozinho na seara do sofrimento diante do contexto de morte.

\section{Conclusão}

A partir das considerações desenvolvidas na discussão dos resultados, pôde-se destacar uma série de repercussões psíquicas que extravasam na forma de sofrimento, muitas vezes silenciado, segundo os significados atribuídos pelos enfermeiros às suas vivências no trabalho junto o paciente em risco ou processo de morte. Essas repercussões parecem ter influência, não apenas no processo de trabalho ou na assistência prestada, mas também no significado que trabalho no contexto da morte assume para os profissionais.

Os resultados remetem à perda da autonomia profissional quando o sujeito enfermeiro se depara com a dificuldade de pensar o seu próprio trabalho. Esse conflito moral afeta negativa- mente a sua percepção de qualidade de vida no ambiente de trabalho e a relação com o próprio paciente e família. Existe um significativo sentimento de angústia relacionada ao tipo de trabalho no contexto da morte, onde, além de ter que lidar com o cuidado à dor do outro, remete às suas próprias dores.

Diante de tal realidade, é notória a necessidade de que instituições de saúde, equipes e o próprio enfermeiro percebam esse profissional como um sujeito ético, que necessita refletir seu trabalho para que haja possibilidade de planejar alguma forma de digerir a angústia do trabalho. Favorecer espaços de escuta desse sujeito cuidador, acreditando que, por meio da fala, possam ser permitidos momentos de reflexão e de escoamento do sofrimento. Além disso, perceber a importância da autonomia profissional do enfermeiro para aliviar a angústia de se deparar com os conflitos morais, inerentes a sua prática, a qual demanda questões normativas e subjetivas.

As limitações deste estudo estão relacionadas à grande mobilização emocional sobre aqueles que são convidados a falar, principalmente, sobre suas angústias no trabalho com pacientes em processo de morte. As recusas em participar deste estudo, ocorridas pela negação ou indisponibilidade de alguns enfermeiros, refletem as angústias expostas nos resultados aqui discutidos. Um trabalho silenciado pela inabilidade do profissional em lidar com as situações de morte e, ainda, pelo temor em falar sobre a sua falta de controle sobre a vida. No entanto, é possível perceber que os participantes deste estudo foram profundos em suas falas, tornando rica a abordagem dos significados que o trabalho tem para cada um deles. Os objetivos da pesquisa clínico-qualitativa são contemplados quando esses significados são captados e os fenômenos devidamente explorados de forma singular.

Os trabalhos subsequentes a esses resultados podem enriquecer as estratégias que favoreçam as práticas de escuta desses profissionais do cuidado. Isso porque, ainda que seja possível que a angústia permeie a prática do enfermeiro no contexto da morte, ao lado do sujeito que sofre há sempre uma potência a ser desenvolvida. 


\section{Referências}

Ariès, P. (2003). História da morte no ocidente. Rio de Janeiro, RJ: Ediouro.

Barbosa, K. K. S., Vieira, K. F. L., Alves, E. R. P., \& Virgínio, N. A. (2012). Sintomas depressivos e ideação suicida em enfermeiros e médicos da assistência hospitalar. Revista de Enfermagem da UFSM, 2(3), 515-522. doi: $10.5902 / 217976925910$

Barlem, E. D., Lunardi, V. L., Tomaschewski, J. G., Lunardi, G. L., Lunardi, W. D., Filho, \& Schwonke, C. R. G. B. (2013). Moral distress: Challenges for an autonomous nursing professional practice. Revista da Escola de Enfermagem da USP, 47(2), 506-510. doi: 10.1590/ S0080-62342013000200033

Barlem, E. L. D., Lunardi, V. L., Lunardi, G. L., Dalmolin, G. L., \& Tomaschewski, J. G. (2012). Vivência do sofrimento moral na enfermagem: Percepção da enfermeira. Revista da Escola de Enfermagem da USP, 46(3), 681-688. doi: 10.1590/S0080-62342012000300021

Borges, M. S., \& Mendes, N. (2012). Representações de profissionais de saúde sobre a morte e o processo de morrer. Revista Brasileira de Enfermagem, 65(2), 324-331. doi: 10.1590/S003471672012000200019

Carnevale, F. A. (2013). Confronting moral distress in Nursing: Recognizing nurses as moral agentes [Special issue]. Revista Brasileira de Enfermagem, 66, 33-38. doi: 10.1590/S003471672013000700004

Colomé, J. S., \& Oliveira, D. L. L. C. (2012). Educação em saúde: Por quem e para quem? A visão de estudantes de graduação em enfermagem. Texto \& Contexto - Enfermagem, 21(1), 177184. doi: 10.1590/S0104-07072012000100020

Foucault, M. (2010). A Hermenêutica do sujeito. São Paulo, SP: Martins Fontes.

Foucault, M. (2014). Vigiar e Punir. Rio de Janeiro, SP: Vozes.

Gimenes, G. F. (2013). Uses and meanings of quality of life in the contemporary discourse on health. Trabalho, Educação e Saúde, 11(2), 291-318. doi: 10.1590/S1981-77462013000200003

Manetti, M. L., \& Marziale, M. H. P. (2007). Fatores associados à depressão relacionada ao trabalho de enfermagem. Estudos de Psicolo- gia (Natal), 12(1), 79-85. doi: 10.1590/S1413294X2007000100010

Minayo, M. C. S. (2010). O Desafio do Conhecimento: Pesquisa qualitativa em saúde. São Paulo, SP: Hucitec.

Pelbart, P. (2008). Vida e morte em contexto de dominação biopolítica [Conferência proferida no Ciclo "O Fundamentalismo Contemporâneo em Questão"]. Instituto de Estudos Avançados (IEA) da USP, 20.

Peterson, A. A., \& Carvalho, E. C. (2011). Comunicação terapêutica na Enfermagem: Dificuldades para o cuidar de idosos com câncer. Revista Brasileira de Enfermagem, 64(4), 692-697. doi: 10.1590/S0034-71672011000400010

Poles, K. \& Bousso, R.S. (2006). Compartilhando o processo de morte com a família: A experiência da enfermeira na UTI pediátrica. Revista Latino-Americana de Enfermagem, 14(2), 207-213. doi: 10.1590/S0104-11692006000200009

Rodney, P., Kadyschuck, S., Liaschenko, J., Brown, H., Musto, L., \& Snyder N. (2012). Moral agency: Relational connections and support. In J. L. Storch, P. Rodney, \& R. Starzomski (Eds.), Toward a moral horizon: Nursing ethics for leadership and practice (pp. 160-187). Toronto, Canada: Pearson Education.

Sanches, P. G., \& Carvalho, M. D. B. (2009). Vivência dos enfermeiros de unidade de terapia intensiva frente à morte e o morrer. Revista Gaúcha de Enfermagem, 30(2), 289-296. Recuperado em http://seer.ufrgs.br/index.php/RevistaGauchadeEnfermagem/article/download/3294/6687

Santos, J. L., \& Bueno, S. M. V. (2010). A questão da morte e os profissionais de enfermagem. Revista de Enfermagem da UERJ, 18(3), 484-487. Recuperado em http://www.facenf.uerj.br/v18n3/ v18n3a26.pdf

Santos, Y. S., Jesus, L. C., \& Portella, S. D. C. (2013). A enfermagem e a abordagem da morte infantil: Um estudo de trabalhos qualis A. Revista Enfermagem Contemporânea. 2(1), 112-131. doi: 10.17267/2317-3378rec.v2i1.252

Souza e Souza, L. P., Mota, R. J., Barbosa, R. R., Ribeiro, G. R. C., Oliveira e Silva, C. S., \& Barbosa, D. A. (2013). A morte e o processo de morrer: Sentimentos manifestados por enfermeiros. Enfermería Global, 12(32), 222-229. Recuperado em http://revista.portalcofen.gov.br/repositorio/ journals/1/pressrelease/006.pdf 
Tschiedel, R. M., \& Monteiro, J. K. (2013). Prazer e sofrimento no trabalho das agentes de segurança penitenciária. Estudos de Psicologia (Natal), 18(3), 527-535. doi: 10.1590/S1413$-294 X 2013000300013$

Turato, E. (2013). Tratado da Metodologia da Pesquisa Clínico-Qualitativa: Construção teórico-espistemológica, discussão comparada e aplicação nas áreas da saúde e humanas. Petrópolis, RJ: Vozes.

Umann, J., Silva, R. M., Benavente, S. B. T., \& Guido, L. A. (2014). O impacto das estratégias de enfrentamento na intensidade de estresse de enfermeiras de hemato-oncologia. Revista Gaúcha de Enfermagem, 35(3), 103-110. doi: 10.1590/1983-1447.2014.03.44642
Vieira. C. A. L., \& Marques, G. H. (2012). Morte, Angústia e Família: Considerações psicanalíticas a partir da Unidade de Terapia Intensiva. Psicanálise \& Barroco em Revista, 10(1), 97108.

Recebido: 20/07/2016

$1^{a}$ revisão: $11 / 05 / 2017$

Aceite final: $17 / 05 / 2017$

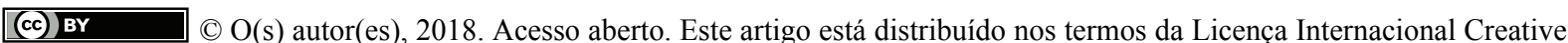
Commons Atribuição 4.0 (http://creativecommons.org/licenses/by/4.0/), que permite o uso, distribuição e reprodução sem restrições em qualquer meio, desde que você dê crédito apropriado ao(s) autor(es) original(ais) e à fonte, fornecer um link para a licença Creative Commons e indicar se as alterações foram feitas. 